\title{
Violência psicológica contra a mulher: Uma análise bibliográfica sobre causa e consequência desse fenômeno
}

\section{Psychological violence against women: a bibliographic analysis of the cause and consequence of this phenomenon}

\author{
Camila Alves Siqueira 1 , Ellen Sue Soares Rocha 2 \\ ${ }^{1}$ Piscóloga, Coordenadora do curso de Psicologia do Instituto Macapaense de Ensino Superior - IMMES. Macapá-AP Brasil. E-mail: \\ psi.camilas@hotmail.com *Autor para correspondência \\ ${ }^{2}$ Acadêmica de Psicologia, Instituto Macapaense do Melhor Ensino Superior. Macapá-AP Brasil. E-mail: ellensue@bol.com.br
}

\author{
Palavras-chave \\ Psicologia \\ Impactos \\ Autoestima
}

\begin{abstract}
A violência psicológica é a forma mais pessoal de agressão contra a mulher, sendo que as palavras tem um forte poder para ferir, fragilizar e impactar a autoestima de uma mulher. Por isso, este artigo visa apresentar resultados e discussão que advém de um projeto de conclusão de curso, que buscou elencar as principais causas que desencadeiam a violência psicológica e verificar os principais prejuízos psíquicos apontados pelos artigos científicos. Desta maneira, foi utilizada a metodologia de pesquisa bibliográfica, de cunho exploratório, qualitativo e descritivo, utilizando-se para análise a perspectiva de trabalho do Bardin sobre análise de conteúdo, e o estudo se baseou em critérios de seleção de busca em cima de palavras chaves previamente pesquisadas, onde encontrou 20 artigos que se incluíam e atendiam aos objetivos da pesquisa, nestes dados as principais causas para a agressão são variadas, porém, em relação à questão psicológica foram elencadas o consumo de álcool, as influências culturais, histórico de violência familiar do agressor, o ciúme, desigualdade de gênero, políticas públicas, entre outros, e detectou-se nos artigos, como consequência da violência psicológica que a mulher pode desenvolver, os autores destacaram as ideações e tentativas de suicídio, transtornos mentais, baixa autoestima, isolamento social, entre outros males. Conclui-se que a violência psicológica traz danos psíquicos irreversíveis a mulher ao longo da vida, impactando negativamente nas diversas instâncias do desempenho das vítimas devido às causas e às consequências desse fenômeno.
\end{abstract}

\section{Keywords}

Psychology

Impacts

Self esteem
Psychological violence is the most personal way of violence against a woman, knowing that words has a strong power to hurt, weaken and impact a woman's self-esteem. Because of that, this study aimed to point the main causes that initiated psychological violence and verify the main psychic damage pointed by scientific articles. Therefore, this work purpose was to make a literature review, in an exploratory, qualitative and descriptive way, based on Bradin's work. With that, databases as Scielo, Lilacs and BVS Psi was chosen, being the articles selected by the pre-defined descriptors found on BVS, like: "violence against the woman and psychology", "violence against the woman and resilience", "violence against the woman and causes", and "violence against the woman and consequences", where it was found 20 articles that were included in the inclusion standard and answered to research goals. The data affirmed that the main causes to aggression were variated, but, relating to the psychological matter, alcohol consumption, cultural influences, familiar aggression in the aggressor history, jealousy, genre inequality, public politics, and others were found as causes. It was detected that in the articles, that as a consequence of psychological violence, woman can develop suicidal ideations and attempts, mental disorders, low self-esteem, social isolation, etc. It can be concluded that psychological violence brings irreversible psychic damages to a woman during her life, impacting negatively several instances of the victim's life, because of this phenomenon causes and consequences.

\section{INTRODUÇÃO}

Segundo Teles e Melo (2012), a violência contra a mulher tornou-se um drama do cotidiano das cidades e países, como o Brasil. Nos últimos anos o assunto da violência psicológica contra a mulher tem se manifestado de forma mais constante, através de profissionais da Imprensa, do Direito e da Saúde.

Atualmente, apesar dos progressos na redefinição do papel da mulher e sua individualidade na sociedade brasileira, ainda há o drama daquelas que lidam com um entendimento equivocado por parte do homem quanto a função da mulher na sociedade, estes não admitem a ascensão e independência da companheira, o que pode desencadear a relação de total domínio do homem sobre a mulher, influenciando, nesse sentido, a prática da violência em suas várias expressões, entre elas, uma muito sutil e silenciosa, mas nem por isso menos danosa: a violência psicológica.

Para as autoras Teles e Melo (2012), o tema é tratado 
muitas vezes como um assunto distante da realidade de quem tem um poder aquisitivo maior. Esse tipo de percepção mostra o reflexo da desigualdade econômica, porém o fenômeno pode acontecer com qualquer mulher independente da sua posição social. Deve-se ter o cuidado e sensibilidade em observar a violência psicológica contra a mulher em sua tênue expressão, pois essa situação pode desencadear consequências graves e até irreversíveis à mulher.

Entende-se que a violência psicológica pode tornar-se o primeiro passo para outros tipos de agressões, tais como: físicas ou até mesmo o feminicídio. Por isso, é uma temática de importante relevância para ser estudada no campo da psicologia.

Esse tema partiu de uma inquietação em entender os motivos que causavam a violência psicológica, pois se concentra nesse assunto exclusivamente o olhar sobre a questão física. Diante disso, a pesquisa que foi realizada se propositava em apresentar aos agentes motivadores da violência psicológica nos dias atuais, apontados por plataformas cientificas, com intuito de compreender esses dispositivos.

Tendo assim, como principal objetivo identificar as principais causas e consequências da violência psicológica sofrida pela mulher brasileira, especificamente elencando os principais motivos que geravam a violência psicológica e apontando as consequências psicológicas vivenciadas pela mulher brasileira.

\section{MÉTODOS}

Durante o processo de pesquisa, é interessante destacar como foi o procedimento de coleta de dados e os resultados, a seguir traçaremos os caminhos metodológicos adotados:

Acessou-se a plataforma Scielo com os seguintes descritores "violência contra a mulher" and "psicologia" e foram encontrados 8 artigos entre 2006 a 2016; com os descritores "violência contra mulher and resiliência" foram encontrados 4 artigos entre os anos 2006 a 2016; e com descritores "violência contra mulher and causas" e "violência contra a mulher and consequências" nenhum artigo foi encontrado, totalizando assim na plataforma Scielo 12 artigos.

$\mathrm{Na}$ plataforma Lilacs foram utilizados os descritores "violência contra a mulher" and "psicologia" e foram encontrados 48 artigos entre 2006 a 2016; Com os descritores "violência contra mulher and resiliência" encontrou-se 3 artigos entre os anos 2006 a 2016; Com "violência contra mulher and causas" foram encontrados 2 artigos; E com "violência contra a mulher and consequências" foram encontrados 3 artigos, totalizando 56 artigos.

Na plataforma BVS PSI foram utilizados os descritores "violência contra a mulher" and "psicologia" onde foram encontrados 40 artigos entre 2006 a 2016; Com descritores "violência contra mulher and resiliência" foram encontrados em 5 artigos entre os anos 2006 a 2016; Com "violência contra mulher and causas" foram 6 artigos encontrados; $E$ com "violência contra a mulher and consequências" encontrou-se 11 artigos, totalizando 62 artigos.

As três plataformas totalizavam em 130 artigos científicos, que foram lidos através do resumo, e neste descartados 100 artigos por não atenderem aos critérios de inclusão ou por não estarem alinhados com a temática. Ficando somente 30 artigos que foram lidos na íntegra e 20 destes responderam aos objetivos desta pesquisa, descriminados no quadro abaixo (Quadro 1).

Os artigos foram elencados em categorias, sendo: as causas da violência psicológica contra a mulher e as consequências da violência psicológica.

\section{RESULTADOS E DISCUSSÃO}

\section{Causas da violência psicológicas contra a mulher}

Os artigos analisados revelaram que as causas da violência contra a mulher são variadas. A partir da análise, foram elencadas todas as causas apontadas pelos autores que correspondiam a violência psicológica. Dos 20 artigos selecionados e analisados, 3 apontaram como causa da agressão a influência cultural.

\section{Influência cultural}

Dos três artigos um concentrou-se na dificuldade que homens e mulheres tem diante das mudanças nos papéis de provedor do lar nos novos moldes da família moderna. Os autores Garcia et al (2008) ressaltaram que o homem tem passado a conviver com a realidade de ter a mulher como sua concorrente no mercado de trabalho e ainda lida, por vezes, com situações do desemprego, tendo que passar a depender financeiramente da mulher, ocasionando não só a perda do poder aquisitivo dentro da família, mas também influenciando negativamente na sua autoimagem. Os autores verificaram que os homens e as mulheres têm encontrado dificuldades em lidar com situações nas quais ele perde o papel de provedor do lar ou quando a mulher passa a ganhar mais que eles. 
Quadro 1. Tabulação dos artigos utilizados para a construção do trabalho.

\begin{tabular}{|c|c|c|c|}
\hline Nome dos autores & Ano & Título & Plataforma \\
\hline $\begin{array}{l}\text { DA FONSECA, P. M.; LUCAS, T. } \\
\text { N.D. S. }\end{array}$ & 2006 & $\begin{array}{l}\text { Violência doméstica contra a mulher e suas } \\
\text { consequências psicológicas }\end{array}$ & BVS psi \\
\hline DANTAS, B. M; MÉLLO, R. P. & 2008 & $\begin{array}{l}\text { Posicionamento críticos e éticos sobre a violência } \\
\text { contra as mulheres }\end{array}$ & BVS psi \\
\hline $\begin{array}{l}\text { JONG, L. C; } \quad \text { SADALA, } \\
\text { A; TANAKA, A. C. D. A. }\end{array}$ & 2008 & $\begin{array}{l}\text { Desistiendo de denunciar al agresor: testimonio de } \\
\text { mujeres víctimas de violencia doméstica }\end{array}$ & Lilacs \\
\hline LEVY, L. GOMES, I. C & 2008 & $\begin{array}{l}\text { Relação conjugal, violência psicológica e } \\
\text { complementaridade fusional. }\end{array}$ & Scielo \\
\hline CERRUTI, M. Q.; ROSA, M. D. & 2008 & $\begin{array}{l}\text { Em busca de novas abordagens para a violência de } \\
\text { gênero: a desconstrução da vítima }\end{array}$ & BVS psi \\
\hline GARCIA, M. V. et al. & 2008 & $\begin{array}{l}\text { Caracterização de casos de violência contra a } \\
\text { mulher atendidas em três serviços na cidade de } \\
\text { Uberlândia, Minas Gerais, Brasil. }\end{array}$ & Scielo \\
\hline ANGELIM, F. P.; DINIZ, C. R. S. & 2009 & $\begin{array}{l}\text { O pessoal torna-se político: o papel do Estado no } \\
\text { monitoramento da violência contra as mulheres }\end{array}$ & Lilacs \\
\hline MOURAL, L. B. A; et al. & 2009 & $\begin{array}{l}\text { Violências contra mulheres por parceiro íntimo em } \\
\text { área urbana economicamente vulnerável, Brasília, } \\
\text { DF. }\end{array}$ & Scielo \\
\hline SCHRAIBER, D'OLIVEIRA, COUTO. & 2009 & $\begin{array}{l}\text { Violência e saúde: contribuições teóricas, } \\
\text { metodológicas e éticas de estudos da violência } \\
\text { contra a mulher }\end{array}$ & Lilacs \\
\hline $\begin{array}{l}\text { TIMM, F. } \quad \text { B.; PEREIRA, } \\
\text { GONTIJO }\end{array}$ & 2011 & $\begin{array}{l}\text { Psicologia, violência contra mulheres e feminismo: } \\
\text { em defesa de uma clínica política }\end{array}$ & Lilacs \\
\hline $\begin{array}{l}\text { GODONI-COSTA, L. M; ZUCATT, } \\
\text { A. P. N; DELL'AGLIO, D. D. }\end{array}$ & 2011 & $\begin{array}{l}\text { Violência contra a mulher: levantamento dos casos } \\
\text { atendidos no setor de psicologia de uma delegacia } \\
\text { para a mulher }\end{array}$ & Scielo \\
\hline NARDI, S. C. S; BENETTI, S. P. D. C & 2012 & $\begin{array}{l}\text { Violência conjugal: estudo das características das } \\
\text { relações objetais em homens agressores }\end{array}$ & Lilacs \\
\hline MONTEIRO, M. F. G; ZALUAR, A. & 2012 & $\begin{array}{l}\text { Violência contra a mulher e a violação dos direitos } \\
\text { humanos }\end{array}$ & Lilacs \\
\hline ROSA, D. O. A et al. & 2013 & $\begin{array}{l}\text { A violência contra a mulher provocada por parceiro } \\
\text { íntimo. }\end{array}$ & Lilacs \\
\hline COLOSSI, P. M; FALCKE, D. & 2013 & Gritos do silêncio: a violência psicológica no casal & Lilacs \\
\hline 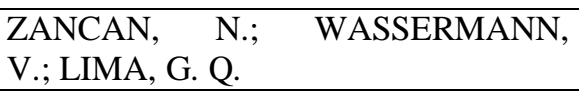 & 2013 & $\begin{array}{l}\text { A violência doméstica a partir do discurso de } \\
\text { mulheres agredidas }\end{array}$ & Scielo \\
\hline $\begin{array}{l}\text { BECCHERI CORTEZ, M; SOUZA, L. } \\
\text { D. }\end{array}$ & 2013 & $\begin{array}{l}\text { Mulheres de classe média, relações de gênero e } \\
\text { violência conjugal: um estudo exploratório. }\end{array}$ & Lilacs \\
\hline $\begin{array}{l}\text { FERNANDES, G. B. GAIA, V. O; } \\
\text { ASSIS, C. } 1 . \text { D }\end{array}$ & 2014 & $\begin{array}{l}\text { Estratégias de enfrentamento da violência de } \\
\text { gênero em mulheres de Ji-Paraná ( } \mathrm{RO})\end{array}$ & Lilacs \\
\hline $\begin{array}{l}\text { SILVA, S. D. A et al. } \\
\text { RESULTADOS }\end{array}$ & 2015 & $\begin{array}{l}\text { Análise da violência doméstica na saúde das } \\
\text { mulheres. }\end{array}$ & Scielo \\
\hline $\begin{array}{l}\text { SILVA, E. B. D; PADOIN, E. M. D } \\
\text { M.; VIANNA, L. A. C. }\end{array}$ & 2015 & $\begin{array}{l}\text { Mulher em situação de violência: limites da } \\
\text { assistência }\end{array}$ & Scielo \\
\hline
\end{tabular}

Verificamos na população brasileira que homens e mulheres têm tido dificuldade em lidar com situações nas quais ele perde o papel de provedor do lar ou naquelas em que a esposa acaba ganhando mais do que o marido. (GARCIA et al, 2008)

Essa definição está de acordo com a definição de Dias (2004), que diz que a violência justifica-se como uma forma de compensar possíveis falhas no cumprimento de papel de gênero. Ou seja, quando o homem que outrora era o responsável pela manutenção do lar, o provedor, agora se vê disputando o mercado de trabalho com a mulher, que culturalmente foi criada para cuidar apenas da casa, da educação dos filhos e da imagem do marido, consequentemente passa a sentir a necessidade de medir forças com a parceira pela insatisfação causada pelas mudanças decorrentes da redefinição dos papéis. Isso nos remete ao fato que a partir desta situação, o homem por se sentir inferior ao lugar que a mulher ocupa, passa a usar de mecanismos para desqualificar a atuação da companheira e isso se dá devido ao fato de não saber lidar com o 
empoderamento e a ocupação de um papel que no seu imaginário deveria ser dele.

Com referência aos outros dois artigos, os autores Rosa et al (2013) e os autores Timm, Pereira, Gontijo (2011), apontam para o papel da mulher dentro das relações patriarcais, onde a mulher assume uma identidade formada a partir do olhar do homem, adquirindo e preocupando-se com os valores morais e culturais, sentindo-se profundamente desamparada.

Os resultados apontam para a relevância da influência cultural como um fator desencadeante da violência contra a mulher. Como consequência dessa influência, há uma padronização de papéis que tem de ser seguido, no qual o homem é a voz máxima dentro da casa e essa voz tem de ser ouvida e atendida prontamente, sendo estabelecidas relações de autoridade, onde o homem passa, diante da autoridade que Ihe foi conferida pela sociedade, a subjugar a mulher, entendendo que para ser obediente precisa ser tolhida e anulada. Tal ideia vem embasada por D'incao (2004), apud Priore (2004), que destaca que sutilmente foi reforçado na mulher a importância do amor familiar e reservado a ela o interior do espaço doméstico, papel endossado por profissionais da saúde e da imprensa na reformulação de uma série de propostas para educar a mulher.

O que percebemos diante do exposto é que desde muito cedo aprendemos a organizar socialmente as nossas concepções a partir da classificação de feminino e masculino. A menina brinca de casinha e boneca, o que remete ao espaço privado do lar, em quanto que o menino brinca com carrinhos e brincadeiras mais desafiadoras, subentendendo o espaço público.

Os artigos parecem afirmar que a mulher continua em situação de agressão por medo de ser mal vista pela sociedade ou por fazer parte de uma família conservadora, onde o divórcio é coisa de mulher sem caráter, perpassando a ideia de que o único a ter direito de escolha e decisão dentro da relação é o homem, que por sua vez tem a visão sobre a mulher de frágil, incapaz de seguir sem ser guiada por uma figura masculina. Teles; Melo (2012) ratifica que a sociedade caracterizou os papéis dos homens e mulheres no decorrer da história e com isso gerou um masculino forte, onipotente, autônomo, objetivo e racional, enquanto que a mulher caracterizou como frágil, sem poder, dependente, emocional, subjetiva e dominada.

A mulher acaba por incorporar esse estigma que se estabelece a partir do processo de construção e internalização da dependência emocional. Fundamentado em Goffman (2008), pode-se considerar que o estigma é, então, na realidade, um tipo especial de relação entre atributo e estereótipo. Ou seja, as informações e características determinadas e transmitidas socialmente, responsáveis por definir a mulher como sendo incapaz de gerir sua própria vida por ser frágil e fraca. Por essa razão passa a sofrer discriminação e muitas vezes exclusão social ou até mesmo redução de chances de vida.

A pesquisa também revelou como causa da violência psicológica contra a mulher a bebida alcoólica. Dos 20 artigos 6 apontaram para o álcool como um facilitador para a agressão contra a mulher.

\section{Bebida alcóolica}

Não houve diferenças significativas entre as pesquisa de Jong, Sadala, Tanaka (2008), Zacan, Wassermmann, Lima (2013), Beccheri e Souza (2013) e Rosa et al (2013), sendo a bebida alcoólica apontada como uma das principais causas da violência. Os resultados mostraram que os parceiros se tornam mais agressivos e impulsivos sob o efeito do álcool, não medindo as consequências por se sentir mais corajoso, transformando-se em outra pessoa, partindo para a ignorância, acuando a vítima com insultos, xingamentos e ameaças.

Isso nos remete a declaração de Teles e Melo (2012), que caracterizando a violência, afirmam que ela é uma forma de coagir, impedir alguém de ter sua vontade própria, enclausurá-la, sob pena de viver gravemente ameaçada ou até mesmo espancada. Vale ressaltar que a alteração que ocorre no homem por conta da bebida alcóolica faz com que ele exerça sobre a mulher atos abusivos sem levar em consideração as consequências que esses atos podem ocasionar à mulher.

As autoras Beccheri e Souza (2013) em sua pesquisa trazem relatos de uma das participantes onde,

(...) Natália relatou que a maior parte de seu relacionamento foi boa, mas nos últimos anos Noel "começou a ficar muito agressivo com as palavras não com socos", depois que passou a beber mais.

A mulher se depara com situações conflitantes, o desamparo vivenciado por elas por não saber lidar com a situação de agressão só agrava ainda mais o quadro de violência, causando dores imensuráveis e invisíveis, que são difíceis de serem sanadas. Esta afirmação baseia-se na afirmação de Dias (2014) que diz que quando a agressão não gera reação, aumenta a agressividade. A autora ressalta que, a ferida nunca sara, os ossos quebrados se recuperam, o sangue seca, mas a perda da autoconfiança, a visão pessimista, a depressão, essas são feridas que não curam. Por isso a autora afirma: é preciso romper o pacto de 
silêncio, não aceitar sequer um grito, denunciar a primeira agressão.

Entretanto, Guerra (2000) apud Garcia et al (2008), adverte que o álcool não é o responsável básico pela violência, mas sim um facilitador para uma situação de agressão já pré-estabelecida.

Praticamente todos os autores concordaram que a bebida alcoólica traz sérios prejuízos aos relacionamentos e torna-se um facilitador para a agressão, uma vez que se torna desculpa para a prática e faz com que a mulher internalize a ideia de que nessas circunstâncias a culpa nunca é do homem e sim da bebida. Ou ainda, a mulher, na tentativa de fazer com que seu parceiro deixe de beber, acaba gerando discussões pela maneira como manifesta sua opinião, levando o homem, diante do impulso, a cometer o ato de agredi-la psicologicamente, levando a vítima a se culpabilizar pela situação. O que confirmam Fonseca, Ribeiro e Leal (2012) ao afirmarem que a mulher sente raiva de si mesma, percebendo-se como seu próprio inimigo, uma vez que não consegue reunir forças para sair da situação de agressão. A culpa também perdura com intenso sofrimento.

Pode-se considerar que a bebida provoca, em muitos casos, variadas implicações negativas para a mulher, podendo ser no ambiente doméstico ou não, porque geralmente esse consumo por parte do homem traz desentendimentos pessoais envolvendo ofensas e violência que causam danos à mulher de diversas formas na saúde física e mental, desgastando o bom funcionamento do âmbito familiar como um todo. Essas experiências vivenciadas pela mulher desenvolve sentimentos de desamparo, deixando-a em uma situação de exposição, uma vez que esse homem a xinga e a humilha prejudicando sua autoestima.

Os resultados da pesquisa nos levaram a considerar que a bebida faz com que os vínculos afetivos se tornem frágeis, permitindo com que cada vez mais sentimentos de insatisfação sejam estabelecidos em ambos os envolvidos. Esses sentimentos parecem reforçar a relação de poder onde o homem é quem domina e a mulher se torna dominada. A insatisfação masculina pode se manifestar de muitas formas, podendo ser uma delas a culpabilização da mulher pelos próprios fracassos e erros, desestabilizando e prejudicando o equilíbrio emocional necessário para que essa mulher tenha uma saúde física, psíquica e emocional estáveis. Dias (2004) corrobora com esta afirmação ressaltando que o agressor sempre atribui a culpa à mulher, tenta justificar seu descontrole na conduta dela, suas exigências constantes, seu desleixo para com a casa e filhos. Alega que foi ela quem começou, pois não faz nada certo, não faz o que ele manda. Ela acaba reconhecendo que ele tem razão, que em parte a culpa é sua. Assim, perdoa e continua no processo de agressão.

Outra causa da violência psicológica contra a mulher encontrada em 4 artigos da análise foi o ciúme.

\section{Ciúme}

Cada artigo traz de forma similar o ciúme como a causa da agressão psicológica mais citada em seu estudo.

O propósito de Nardi e Benetti (2012) e Baccheri e Souza (2013) é apresentar dados que mostram o quanto o ciúme está ligado a ideia de que a mulher é uma propriedade particular e que o homem é o detentor do direito de poder, como consequência a mulher desenvolve sentimentos como a insegurança e dependência.

Os autores Fonseca; Ribeiro; Leal (2012) ratificam que as vítimas desenvolvem insegurança nos sentimentos demonstrados, uma vez que variam de um extremo a outro, podendo ser inferidas dessas relações questões relacionadas ao domínio da relação pelo homem (relação de poder), em que se observam comportamentos de submissão, ingenuidade e vulnerabilidade.

A proposta dos autores envolve a preocupação em levarnos a refletir sobre a romantização do ciúme, quando a mulher percebe o ciúme como um cuidado ou amor.

Entretanto, os autores Garcia et al (2008), apontaram o ciúme como um desencadeador de insegurança masculina, por conta da juventude ou do corpo bonito da mulher, ocasionando no homem comportamentos de controle sobre a vontade da mulher.

Garcia et al (2008), diz que,

(...) nessa faixa etária o corpo é belo e desperta atenção, o que poderia provocar nos homens inseguranças, e práticas autoritárias violentas, o que explicaria no presente estudo a diminuição da ocorrência de agressão à mulher a partir da quarta década de vida.

Portanto, os comportamentos baseados em ciúmes acabam por naturalizar comportamentos que podem evoluir para a agressões mais sérias. O ciúme passa despercebido, visto como algo que é inerente nas relações por isso tão aceitável pela mulher. Em outras palavras, a ausência de ciúme seria vista como ausência de amor, caracterizando-se, assim, como causa da violência psicológica.

\section{Políticas públicas}

Em quatro artigos analisados, os autores apontaram como causa da violência psicológica contra a mulher as 
políticas públicas. Ao considerar os achados dessa pesquisa percebe-se que os autores - Timm, Pereira e Gontijo (2011), Silva, Padoin e Vianna (2013) e Rosa et al (2013) consideram que a dificuldade da mulher em denunciar a violência e, assim, permanecer vinculada ao agressor se dá pela dificuldade de contar com o apoio de políticas públicas que por vezes, na intenção de oportunizar à mulher autonomia, a restringe novamente a um lugar de um ser frágil. Há ainda o despreparo por parte dos profissionais que atendem esse tipo de demanda, não oferecendo o acolhimento e a segurança necessária para que a vítima se sinta protegida.

$\mathrm{Na}$ pesquisa dos autores Rosa et al (2013) destaca-se que:

“Essa concepção ilumina o percurso a ser trilhado: trata-se de examinar essa assimetria, pois o que se verifica é o quanto as atuais políticas públicas, em sua tentativa de dar autonomia à mulher, a partir de medidas jurídicas específicas, acaba justamente por confina-la novamente a um lugar de fraco, vulnerável, frágil e vitimizado".

Essa declaração está de acordo com a afirmação de Dias (2004). Segundo a autora, a dificuldade dos operadores do direito em se conscientizar da necessidade de um tratamento diferenciado para a mulher contribui para que se chegue a um nível elevado de violência. Por esse motivo, conclui que a lei veio na contramão da história. Desburocratizando a justiça criminal, acabou mais uma vez por sacrificar a mulher.

A mulher, nessas circunstâncias, desiste de denunciar por achar que não vai dar em nada. Assim, a violência psicológica perdura até evoluir para agressões mais graves.

Por sua vez, os autores Beccheri e Souza (2013) relacionaram à causa da violência psicológica contra a mulher o machismo, que é ainda tão operante dentro do judiciário. Comportamentos preconceituosos de quem é destinado para dar suporte a vítima dificultam o andamento dos processos. Nesses casos observa-se a facilitação para a absolvição do agressor. Dessa forma, a mulher passa a ficar descrente com relação às redes de apoio, permanecendo, assim, em situação de agressão.

As autoras Beccheri e Souza (2013) em sua pesquisa diz,

(...) Encontramos em diversos estudos reiterações de que no judiciário permanecem preconceitos e normas tradicionais de gênero que muitas vezes guiam discursos de defesa e acusação e também sentenças. Neste caso fica a denúncia de má conduta de um (ou mais um) defensor público que, contratado pelo Estado para defender sua cliente, se vale de argumentos machistas e ameaçadores, e possivelmente também de seu conhecimento sobre as diversas falhas no sistema de proteção à mulher, para convencer Joana a retirar o processo contra Jorge.

Dias (2004) corrobora com as autoras, ressaltando de que não é a justiça, mas a sociedade machista que absolve os homens.

A partir do exposto, nota-se no judiciário o preconceito sobre a mulher que vive em busca dos seus direitos, mas que por questões de maturação psicológica ou do próprio ciclo da agressão demora a romper com tal violência, assim a mulher é vista como aquela que gosta de sofrer, aquela que aceita e concorda, pois já deveria ter cortado os laços com o agressor. Em vista disso, percebe-se que, apesar das reformas no campo jurídico que sustentam o direito da mulher, há ainda o despreparo dos profissionais que dificulta a aplicabilidade da lei, e que geralmente, ou facilitam a impunidade, ou não dão a devida importância a esse fenômeno por trazerem consigo o preconceito com a vítima, pelo fato de ainda vê-la como um ser inferior que não exige cuidados. De fato, essas lacunas deixadas pela justiça vem sendo consideradas como um importante fator desencadeador da violência psicológica contra a mulher, pois estendem a violência ocorrida por parte do companheiro, reforçando os sentimentos de desamparo.

Outra causa da agressão psicológica encontrada nos artigos foi a desigualdade de gênero, 2 artigos apontaram para esse agente.

\section{Desigualdade de gênero}

Houve concordância entre os autores Monteiro e Zaluar (2012) e os autores Zacan, Wassermann e Lima (2013) quando se referem a desigualdade de gênero como uma das causa da violência psicológica contra a mulher, reconhecendo que essa ação passa a produzir círculo viciosos de concepções e comportamento que afetam tanto a vítima quanto as pessoas que estão sob os cuidados dela. Seguindo o raciocínio dos autores, nota-se que a sociedade tem sua parcela de contribuição para a formação da visão de superioridade masculina sobre a mulher, categorizando papéis a serem seguidos por ambos, onde geralmente o homem é o que tem direitos para galgar posições elevadas, 
enquanto a mulher fica com papéis geralmente dirigidos para o interior do lar.

A pesquisa dos autores Zacan; Wassermann; Lima (2013), diz que,

(...) Na relação conjugal, a desigualdade de gênero é mais presente, principalmente nos modelos tradicionais de família e casamento, nos quais a posição de provedor econômico configura-se no homem, e a de mãe e cuidadora do lar, na mulher. Ainda, a mulher é mais propensa às relações desiguais de poder, de tal modo que os aspectos característicos da masculinidade confirmam as relações de dominação sobre as mulheres.

Ao analisar essa perspectiva, observa-se que a partir da classificação dos papéis sociais a mulher foi ficando cada vez mais subjugada pela superioridade masculina. Dentro da família o homem assume o papel de provedor, aquele que sai pra trabalhar, o que tem autonomia para mandar até mesmo na vontade da mulher, enquanto que a ela fica a tarefa de cuidar do lar e da prole.

Esta ratificação está de acordo com a afirmação de Bacilla (2005) apud Ribeiro (2013), onde ressalta que não existia uma definição de papéis a priori, onde definia a superioridade masculina com relação a mulher, essa ação se deu a partir do processo cultural de repetição, que se desenvolveu por causa de circunstâncias aleatórias. A partir desse processo a mulher passou a introjetar como verdade a sua incapacidade de deixar os filhos e a privacidade do lar para assumir posições mais desafiadoras, ficando categorizado os respectivos papéis destinados a cada um. A partir desse movimento a mulher passou a aceitar a condição de responsável pelo bem estar dos filhos e do marido, estando sempre abaixo deste, enquanto que ele, por sua vez, passou a demarcar seu espaço como o superior, detentor do poder sobre a mulher, deixando-a em uma situação de vulnerabilidade por não ter voz ativa.

\section{Visão conservadora}

Três artigos apontam na análise como a causa da violência contra a mulher a visão conservadora.

Verifica-se a mesma intenção nos autores Dantas e Mello (2008), Beccheri e Souza (2013), Nardi e Benetti (2012) em apontar a visão conservadora como causa do abuso psicológico contra a mulher, visão essa que geralmente é perpassado de pai para filho.

$\mathrm{Na}$ análise das pesquisas dos autores podemos perceber como causa a ameaça que os homens sentem frente ao empoderamento da mulher que pode destruir com o status que faz deles uma autoridade masculina. Assim, o homem se torna agressivo, individualista, egocêntrico, nega-se a ouvir opinião ou qualquer ação que possa fazê-lo concordar com a mulher.

Costa; Barker (2003), apud Dantas e Méllo (2008) traz em sua pesquisa resultados onde:

(...) revelou que visões conservadoras e tradicionais sobre o que significa ser homem estavam altamente relacionadas ao uso da violência contra as mulheres.

Seguindo essa perspectiva, o homem parece se enxergar como aquele que tem de zelar pelo legado deixado por seus antepassados conservadores, cuidando e reforçando a imagem de homem dominador, que não precisa respeitar a mulher, e sim, impor-se para ser respeitado. Dessa forma, entende que o único meio de continuar sendo temido e reverenciado é através da violência, do temor e da inferioridade que desperta na mulher através de atitudes agressivas. Teles e Melo (2012) concordam com a afirmação dos autores quando alegam que, [...] A garantia da supremacia masculina dependia única e exclusivamente da inferioridade feminina. [...].

Em vista do exposto, considera-se a necessidade masculina de manter relações de poder para não perder o controle da relação, não admitindo a possibilidade de empoderamento da mulher, haja vista que esta tem papéis na sociedade bem diferentes e menos importantes do que o dos homens. Nesse sentido, fica claro a necessidade do homem em anular e tolher a mulher, na intenção de mostrar todo seu autoritarismo do qual se orgulha, mantendo contínuo desrespeito com os direitos da mulher.

Seguindo com os achados sobre o abuso psicológico, 3 artigos elencaram o histórico de violência familiar do agressor como causa da violência contra a mulher.

\section{Histórico de violência familiar do agressor}

A partir dos artigos analisados, foi observado considerações similares dos autores sobre o histórico de violência familiar como causa de agressão contra a mulher. As afirmações de Colossi e Falcke (2013), Zacan, Wassermann e Lima (2013), Nardi e Benetti (2012) apontam para vivências abusivas durante a infância dentro de casa por parte dos pais como origem de muitos comportamentos agressivos dos homens. Em vista disso, a mulher passa a justificar os atos violentos dispensados a ela, acreditando ser reflexos dos traumas de seus companheiros. 
Ainda os autores Zacan; Wassermann; Lima (2013) mostram:

Nesse contexto, o homem é visto como vítima de si mesmo, doente, impulsivo e descontrolado. Desse modo, a compreensão da violência nas relações conjugais é um aspecto que dificulta as rupturas, reafirmando a impotência da mulher para o enfrentamento do problema. (...) Ele (cônjuge) sofreu bastante durante a infância também, o pai era agressivo com os filhos. Se criou assim, o pai e a mãe bebendo dia e noite, não tinha amor de mãe, não tinha amor de pai. Acho que isso aí também ajuda, né? (Márcia).

Partindo dessa ideia, verifica-se a dificuldade de enfrentamento e resiliência nas mulheres que sofrem agressão dos companheiros, por acreditar que o comportamento agressivo é fruto das experiências que sofreram quando criança. Dessa forma, a violência não é vista como falta de amor, mas sim, uma ação impensada de alguém que também foi vítima.

A pesquisa das autoras Fonseca, Ribeiro e Leal (2012) ratificam essa afirmação trazendo uma declaração de uma das participantes de sua pesquisa que diz: (...) Deve ter sido pelo pai que também era violento/ e ele foi criado só pelo pai.

Assim, as mulheres se sentem presas nessas relações, pois acreditam que o comportamento só existe por conta de suas experiências negativas na infância, permitindo o homem fazer uso de formas violentas para alcançar seus objetivos e satisfação pessoal.

\section{Interrupção do apoio da família}

A pesquisa de Fonseca (2006) aponta como causa a falta de apoio por parte da família. Quando a vítima tem por perto membros familiares nos quais a mulher pode confiar o suficiente para contar sobre as agressões psicológicas que sofre, há maiores chances de evitar sua incidência. Porém, quando a mulher não tem uma boa relação com familiares dá ao agressor um leque de oportunidade para agredi-la com facilidade.

Moura et al. (2009), corroboram com a afirmação das autoras Fonseca e Lucas (2006) ratificando que a violência psicológica contra a mulher está associada à redução do apoio oferecido pelos membros da família. Percebe-se diante desta afirmação, que quando a vítima tem interrompida a dinâmica familiar, que lhe permite ser assistida de perto pelos seus componentes íntimos, entra em um estado de vulnerabilidade maior, por se encontrar sozinha, oportunizando ao agressor a manutenção dos episódios de violência.

\section{Consequências psicológicas da violência contra a mulher}

Após sofrer violência psicológica, a mulher pode apresentar como consequências diversos sintomas. Por isso para responder ao segundo objetivo específico da pesquisa, buscou-se apontar todas as consequências da violência psicológica encontrados nos artigos analisados.

Foi verificado nos artigos dos autores Silva et al (2015) que, como consequência da violência psicológica, as mulheres ficam:

- Prejudicadas em sua vida social

- Reprimidas

- Psicologicamente abaladas

Importante observar que as consequências da violência psicológica comprometem toda a estrutura psíquica, física e social da mulher. De acordo com os autores Silva et al (2015), a vítima perde o interesse em cuidar-se, isola-se, sente-se cansada, mentalmente esgotada, tendo perdas significativas na qualidade de vida.

Fonseca; Ribeiro e Leal (2012) ratificam a análise dos autores com base em seus estudos, onde,

(...) As vítimas relataram que muitas vezes negam a situação, encobrem, escondem, não demonstram em público, ficam reclusas, não saem de casa, limitam-se socialmente restringindo as amizades, vivendo praticamente em condições de confinamento.

A partir dessa análise observa-se que a violência psicológica compromete o estilo de vida da mulher em muitas esferas. Leva a distorção de pensamentos, fazendo acreditar de que não é importante, merecedora de reconhecimento nem de respeito. A violência psicológica agride sua vontade de estar com outras pessoas, família e amigos. Com a harmonia destruída sofrem caladas, sem coragem de compartilhar as vivências sofridas com mais ninguém, essas implicações tornam-na vulnerável, ficando mentalmente fragilizada, o que pode ocasionar mais tarde doenças psicossomáticas como depressão, ansiedade entre outros males.

Segundo Schraiber, Oliveira e Couto (2009), Levy e Gomes (2008), e Fonseca; Ribeiro; Leal (2012), a violência contra a mulher tem como significado mais agravado em sua 
saúde:

- Ideações e tentativas suicidas

- Transtornos Mentais

- Autodesqualificação/Baixa autoestima

- Perda identidária de sujeito

Segundo os autores Schraiber, Oliveira e Couto (2009), e Levy e Gomes (2008), a mulher que sofre agressões psicológicas, vivencia sentimentos que geralmente desconhece em si e quando não se dá a importância necessária para trata-las, pode progredir para sentimentos negativos e mais graves.

Melo et al. (2005) apud Godoni-Costa, Zucatti e Dell'Aglio (2011) corroboram com esses dados salientando que, quanto mais intensa a violência, seja ela física ou verbal, mais intensos serão seus prejuízos para a vítima, compreendendo desde depressão, comportamentos antissociais, até resoluções inadequadas de problemas que podem resultar em suicídio.

Levando em consideração os achados dessa pesquisa, percebe-se que a perda da autoestima pode desencadear situações muito perigosas, uma vez que, ficando abalada, a mulher não terá a mesma segurança, força para resolver os conflitos, causando sentimento de insegurança e queda de rendimento em outros campos da vida.

Um cotidiano repleto de momentos que causam tristeza, dor, rancor, desqualificação, pode levar uma mulher a sofrer depressão contínua, que com certeza, altera totalmente sua qualidade de vida agravando ainda mais seu quadro. Quando a mulher não consegue sair dessa dinâmica conturbada e não consegue tratar adequadamente seus transtornos, como ansiedade, depressão ou outros, corre o risco de incorrer no erro em buscar falsas soluções para o problema, estando mentalmente presa a sentimentos que podem levar, sem pensar, a cometer tentativas de suicídio.

Monteiro e Souza (2007), Apud Zacan; Wassermann; Lima (2013) Fernandes; Gaia; Assis (2014), e Cerruti (2008) concordam que, como consequência da violência psicológica, a mulher agredida torna - se:

- Frágil

- Dependente do sofrimento

- Torna-se vítima do seu próprio pesadelo

Os autores parecem afirmar que mulheres vítimas de violência psicológica se veem presas a um enlace psíquico que faz com que elas, com o tempo, se tornem fragilizadas e dependentes dessa agressão, por perceber a violência como algo que faz parte da relação. Fonseca; Ribeiro; Leal (2012) concordam com os autores apontando em seu trabalho relatos de participantes vítimas de agressão psicológica, onde relatam que, devido ouvirem constantemente de seus parceiros que não servem nem para os afazeres da casa, desmoralizando sua beleza, amedrontando-as com a possibilidade de arranjar uma mulher mais bonita, fazem com que se sintam de fato desvalorizadas, acreditando que precisam suportar tal humilhação por não ter condições de seguir sem o parceiro.

Nesse sentido, percebe-se que os efeitos da violência psicológica são impedimentos muito penosos para uma mulher que lida com rejeição diariamente, escuta o tempo todo que não vale nada, é xingada e menosprezada. Pode ser muito difícil entender que a situação de agressão não é natural, não faz parte de relacionamentos saudáveis e que, portanto, não tem que aceitar.

Na pesquisa realizada por Colossi; Falcke (2013) vemos através do relato de uma das participantes que as consequências da violência psicológica podem advir de uma relação marcada por discursos agressivos e violentos, revelando a tendência à repetição dos padrões de comportamento. Os autores compreendem a violência conjugal como expressão da conjugalidade, em que tanto o homem quanto a mulher são responsáveis, em alguma medida, pelo estabelecimento do fenômeno violento. Nestes casos, percebe-se na mulher:

- Frustração

- Revida com explosões de raiva

- Ofensas e humilhação

- Dificuldade em resolver os problemas

- Tendência ao afastamento físico

- Manutenção do seu descontentamento em silêncio

Fonseca, Ribeiro e Leal (2012) confirmam a pesquisa dos autores, pois, destacam que a mulher em contato com o agressor pode ir moldando-se através dos comportamentos repetitivos que vivencia, vindo a agir e reagir também com violência. Em seu estudo Fonseca; Ribeiro e Leal (2012) trazem um trecho do relato de uma das participantes que diz: (...) A pessoa se torna quase igual à outra pessoa/ vai aprendendo/ Tanto aprende o que é bom e aprende o que é ruim, sabia? / Aprende mesmo (...)

Diante dos expostos pelos autores percebemos que cada mulher reage de uma forma diferente. Há aquelas que sofrem agressão psicológica, porém, ficam quietas, inertes por medo de que a situação se agrave, ou porque já estão esgotadas demais psicologicamente para rebaterem as ofensas que recebem do homem e outras que, com o tempo, passam a revidar diante das frustrações, maus tratos e humilhações e, não conseguindo se conter, explodem trazendo à tona a raiva que guardavam, raiva do desmerecimento de anos.

Outras consequências apontadas pelos artigos encontram-se na pesquisa de Beccheri e Souza (2013), que traz trechos em que as participantes dizem sentir,

\section{- Sensação de insegurança}


- Medo

Meneghel e Hennington (2007) apud Gadoni-Costa, Zucatt e Dell'Aglio (2011) corroboram com essas informações e salientam que a mulher pode entrar em estado de sensibilidade e vulnerabilidade que decorre da situação de violência, causando efeitos negativos e permanentes na autoimagem da mulher, deixando-a insegura sobre seu valor. Encontra-se ainda relação entre a insegurança e o medo por ter, diante dos momentos de violência, menos condições de se proteger por se achar fragilizada.

Zacan; Wassermann; Lima (2013), e Angelim e Diniz (2010) ressaltam a consequência da violência que se apresenta como,

- Isolamento Social

- Solidão

Os autores concordaram que quando a vítima se encontra em processo de agressão, ela tende a se isolar, construindo muros de proteção ao redor de seus sentimentos, não tendo forças e coragem de se expor. Consequentemente, sente-se sozinha, porque passa a se eximir da companhia dos amigos e família. Os autores Fonseca; Ribeiro; Leal (2012) ratificam a afirmação dos autores, mostrando em seu estudo feito com mulheres em situação de agressão o quanto que ficam prejudicadas emocionalmente e socialmente. Uma vez que se sentem renegadas, humilhadas e desvalorizadas pelos homens, (...) Eu me sinto sozinha, sinto que não posso reagir, que nem, todas às vezes que eu tentei sair de casa. (ZACAN; WASSERMANN; LIMA, 2013).

Desse modo, a mulher segue sem permitir qualquer tipo de enfrentamento, sentindo-se desesperançada, haja visto que homens violentos dificilmente reconhecem seus erros e buscam mudanças

A pesquisa apontou como mais uma consequência da violência psicológica o uso de medicamentos psiquiátricos.

Godoni-Costa, Zucatti e Dell'Aglio (2011) informam em seus estudos realizados com mulheres agredidas psicologicamente que, por conta das agressões que sofrem passam a fazer uso principalmente de antidepressivos e ansiolíticos. Para os autores, as mulheres em situação de violência tem mais chances de desenvolver doenças psiquiátricas e, consequentemente, fazer uso de psicofármaco. Pitanguy (2013) ratifica o exposto dos autores, confirmando em seus estudos que a violência se traduz também em incidências no maior uso de serviços de saúde e de medicamentos. Percebe-se, a partir dos expostos, a necessidade da vítima em buscar nos medicamentos alívios para seus traumas, uma vez que, em situação de violência psicológica, o estado psicológico/emocional da vítima fica extremamente abalado.

\section{CONCLUSÕES}

A pesquisa que teve indicou que a violência psicológica é um fenômeno que está presente no cotidiano de muitas mulheres, independente de classe, cor, credo, escolaridade e que prejudica a qualidade de vida da mulher que vivencia esse fenômeno.

Percebeu-se, ainda, que durante o percurso de 10 anos de lei Maria da Penha, os artigos nos anos iniciais da lei não davam destaque à categoria da violência psicológica, enfatizando apenas a questão física. Em meados de 2008 esses resultados começavam a vir à tona, tendo a manutenção de artigos até em 2015. Porém, destaca-se a necessidade da continuação da escrita e publicação para o enfoque da violência psicológica.

Os artigos demonstraram que as principais origens das causas advêm do consumo do álcool, do ciúme, da influência cultural e que, por si só, a causa já denota algumas consequências para a vida desta mulher que vivencia a violência doméstica. Porém, destaca ainda, que esses prejuízos são devastadores para a vítima envolvendo a capacidade de resolução dos problemas, fazendo com que a mulher se sinta envergonhada e humilhada, podendo vivenciar quadros de depressão, por se sentir incapaz de se relacionar com outras pessoas, chegando a se isolar socialmente, trazendo por vezes o uso de medicamentos controlados e podendo gerar a ruptura da estrutura psicológica. Em consonância com a literatura, o principal agressor encontra-se dentro de casa, sendo companheiro, seguido de familiares, gestores, que reforçam a violência vivenciada.

Faz-se necessário destacar a importância do desenvolvimento e melhora das políticas públicas e da prestação dos serviços que contém os profissionais que visam o atendimento desse tipo de demanda, pois a mulher precisa ser acolhida e escutada. Da mesma forma, são necessárias intervenções das redes de apoio junto a família que também sofrem com os efeitos da violência.

Quanto às limitações da realização desta, a primeira se deu pelos poucos achados relacionados a violência psicológica contra a mulher, pois os artigos trazem informações de forma generalizada sobre o fenômeno, dificultando a coleta de dados e prejudicando a estimativa de sua real amplitude. Outra dificuldade está relacionada ao desfecho dos casos de agressão psicológica, uma vez que abrange uma gama de eventos e não há por parte das políticas públicas um olhar diferenciado para esse acontecimento e suas particularidades, deixando prejudicada a definição da natureza do fenômeno.

Espera-se oportunizar conhecimento sobre as variáveis 
da violência psicológica contribuindo a nível de conhecimento e exploração do fenômeno.

\section{REFERÊNCIAS}

ANGELIM, F. P.; DINIZ, G. R. S. O pessoal torna-se político: o papel do Estado no monitoramento da violência contra as mulheres. Disponível

em: <http://pesquisa.bvsalud.org/portal/resource/pt/lil677140>. Acesso em: 19 de Agosto de 2016.

BARDIN, L. Análise de Conteúdo. Lisboa, Portugal; Edições 70, LDA, 2009.

BECCHERI CORTEZ, M.; SOUZA, L. de. Mulheres de classe média, relações de gênero e violência conjugal: um estudo exploratório. Disponível em: <http://www.scielo.org.co/pdf/rgps/v12n24/v12n24a03. pdf $>$. Acesso em: 24 de Julho de 2016.

COLOSSI, P. M.; FALCKE, D. Gritos do Silêncio: A Violência Psicológica no Casal. Disponível em: <http://saudepublica.bvs.br/pesquisa/resource/pt/lil740783> Acesso em: 21 de Julho de 2016.

COUTINHO, R. C. (org). O enfrentamento à violência doméstica e familiar contra a mulher: uma construção coletiva. CNPG, 2011.

CERRUTI, M. Q.; ROSA, M. D. Em busca de novas abordagens para a violência de gênero: a desconstrução da vítima. Disponível em: http://pepsic.bvsalud.org/pdf/malestar/v8n4/09.pdf Acesso em: 20 de Agosto de 2016.

DANTAS, B. M.; MÉLLO, R. P. Posicionamentos críticos e éticos sobre a violência contra as mulheres. Disponível em: <http://dx.doi.org/10.1590/S0102 $71822008000400011>$. Acesso em: 21 de Julho de 2016.

DIAS, M. B. Conversando sobre justiça e os crimes contra as mulheres. Porto Alegre: livraria do Advogado ed., 2004.

FERNANDES, G. B.; GAIA, V. O.; ASSIS, C. L. de. Estratégias de enfrentamento da violência de gênero em mulheres de JiParaná (RO). Disponível em: <http://pesquisa.bvsalud.org/portal/resource/pt/lil783449>. Acesso em: 19 de Agosto de 2016.

FONSECA, D. H.; RIBEIRO, C. G.; LEAL, N. S. B. Violência doméstica contra a mulher: realidade e representações sociais. Disponível em: $<$ www.scielo.br/scielo.php?script=sci_arttext\&pid=S0102 $-71822012000200008 \&$ Ing=pt\&nrm=iso\&tlng=en8>. Acesso em:28 de abril de 2016.

DA FONSECA, P. M.; LUCAS, T. N. S. Violência doméstica contra a mulher e suas consequências psicológicas. Disponível em: <http://newpsi.bvspsi.org.br/tcc/152.pdf>. Acesso em: 20 de Julho de 2016.
GIL, R. L. Tipos De Pesquisa. Disponível em: <http://wp.ufpel.edu.br/ecb/files/2009/09/Tipos-dePesquisa.pdf>. Acesso em: 30 de Julho de 2016.

GARCIA, M. V.; RIBEIRO, L. A.; JORGE, M. T.; PEREIRA, G. R.; RESENDE, A. P. Caracterização dos casos de violência contra a mulher atendidos em três serviços na cidade de Uberlandia, Minas Gerais, Brasil. Disponível em: $<w w w . s c i e l o . b r / s c i e l o . p h p$ ?script=sci_arttext\&pid=s0102 $-311 \times 2008001100010>$. Acesso em: 20 de Agosto de 2016.

GODONI - COSTA, L. M.; ZUCATT, A. P. N.; DELL'AGLIO, D. D. Violência contra a mulher: levantamentos dos casos atendidos no setor de psicologia de uma delegacia para mulheres. Disponível em: <http://dx.doi.org/10.1590/S0103-166x2011000200009> Acesso em:28 de abril de 2016.

GOFFMAN, E. Estigma: notas sobre a manipulação da identidade deteriorada. 4ạ ed.- Rio de Janeiro: LTC, 2008.

JONG, L. C.; SADALA, M. L. A.; TANAKA, A. C. D. Desistindo da denúncia ao agressor: relato de mulheres vítimas de violência doméstica. Disponível em: http://pesquisa.bvsalud.org/portal/resource/pt/lil500604 Acesso em : 19 de Agosto de 2016.

LEVY, L.; GOMES, I. C. Relação conjugal, violência psicológica e complementaridade fusional. Disponível em: <http://www.scielo.br/scielo.php?pid=S01035665200800 0200012\&script=sci_abstract\&tIng=pt Aceso em: 18 de Julho de 2016>.

MOURA, L. B. A.; GANDOLFI, L.; VASCONCELOS, A. M. N.; PRATESI, R. Violências contra mulheres por parceiro íntimo em área urbana economicamente vulnerável. Brasília - DF. Disponível em: <http://www.scielo.br/pdf/rsp/v43n6/0509.pdf> Acesso em 28 de abril de 2016.

MONTEIRO, M. F. G.; ZALUAR, A. Violência contra a mulher e a violação dos direitos humanos. Disponível em: <http://pesquisa.bvsalud.org/portal/resource/pt/lil743170>. Acesso em: 20 de Agosto de 2016.

NARDI, S. C. dos S.; BENETTI, S. P. da C. Violência conjugal: estudo das características das relações objetais em homens agressores. Disponível em: <http://pesquisa.bvsalud.org/portal/resource/pt/lil676524>. Acesso em: 19 de Agosto de 2016.

PITANGUY, J. Violência contra a Mulher: consequências socioeconômicas. Disponível em: <www.kas.de/wf/doc/11287-1442-5-30.pdf> Acesso em: 10 de maio de 2016.

PRIORE, M. Del (org.) História das Mulheres no Brasil. São Paulo: Editora Contexto, 2004.

RIBEIRO, D. de P. Violência contra a Mulher. Brasília: Gazeta Jurídica, 1ae ed., 2013. 
ROSA, D. O. A.; RAMOS, R. C. de S.; MELO, E. M. de; MELO, V. H. A violência contra a mulher provocada por parceiro íntimo. Disponível em: <http://pesquisa.bvsalud.org/portal/resource/pt/lil694480>. Acesso em: 18 de agosto de 2016.

SILVA, L. L. da; COELHO, E. B. S.; CAPONI, S. N. C. Violência Silenciosa: violência psicológica como condição da violência física doméstica. Disponível em: <http://dx.doi.org/10.1590/S1414-

328320007000100009> Acesso em: 10 de maio de 2016.

DA SILVA, E. B.; PADOIN, S. M. de M.; VIANNA, L. A. C. Mulher em situação de violência: limites da assistência. Disponível em: <http://www.scielo.br/scielo.php?pid=S141381232015000100249\&script=sci_arttext\&tlng=pt Acesso em: 20 de Agosto de 2016>.Acesso em: 20 de Agosto de 2016.

SOARES, B. M. Enfrentando a violência contra a mulher. Orientação pratica para profissionais e voluntários. Disponível

em: <http://Iproweb.procempa.com.br/pmpa/prefpoa/cgvs/u su_doc/ev_vio_ta_2005_enfrentando_a_violencia_contr a_a_mulher.pdf $>$. Acesso em: 08 de abril de 2016.

SOUZA, S. D. de. Corpo de mulher e violência simbólica. Disponível em <http://www.koinonia.org.br/tpdigital/uploads/TP\%2032 2.pdf>. Acesso em 28 de abril de 2016.

SILVA, S. de A.; LUCENA, K. D. T. de; DEININGER, L. de S. C.; COELHO, H. F. C.; VIANNA, R. P. de T.; ANJOS, U. U. dos. Análise da violência doméstica na saúde das mulheres. Disponível em: <http://pesquisa.bvsalud.org/portal/resource/pt/lil765989> Acesso em: 21 de julho de 2016.

SCHRAIBER, L. B.; D'OLIVEIRA, A. F. P. L.; COUTO, M. T. Violência e saúde: contribuições teóricas, metodológicas e éticas de estudos da violência contra a mulher. Disponível em: <http://pesquisa.bvsalud.org/portal/resource/pt/lil522229>. Acesso em 18 de agosto de 2016.

TELES, M. A. de A.; MELO, M. de. O que é violência contra a mulher. São Paulo: Brasiliense, 2012 - Coleção primeiros passos.

TIMM, F. B.; PEREIRA, O. P.; GONTIJO, D. C. Psicologia, violência contra mulheres e feminismo: em defesa de uma clínica política. Disponível em: <http://pesquisa.bvsalud.org/portal/resource/pt/lil693277> Acesso em 19 de Agosto de 2016.

ZANCAN, N.; WASSERMANN, V.; LIMA, G. Q. de. A violência doméstica a partir do discurso de mulheres agredidas. Disponível em: $<$ http://pepsic.bvsalud.org/scielo.php?script=sci_arttext
\&pid=S1679-494X2013000100007 >. Acesso em: $21 \mathrm{de}$ Julho de 2016.

Submissão: 04/12/2018

Aprovado para publicação: 10/01/2019 